\title{
Differences in the Levels of the Selected Phytoestrogens and Stable Isotopes in Organic vs. Conventional Hops and Beer
}

\author{
Jelena B. Golubović ${ }^{1, *}$, Ester Heath ${ }^{1,2}$, Iztok Jože Košir ${ }^{3}{ }^{\circledR}$, Nives Ogrinc ${ }^{1,2}$, Doris Potočnik ${ }^{1}$, Lidija Strojnik ${ }^{1}$ \\ and David Heath ${ }^{1}$ \\ 1 Jožef Stefan Institute, 1000 Ljubljana, Slovenia; ester.heath@ijs.si (E.H.); nives.ogrinc@ijs.si (N.O.); \\ doris.potocnik@ijs.si (D.P.); lidija.strojnik@ijs.si (L.S.); david.heath@ijs.si (D.H.) \\ 2 Jožef Stefan International Postgraduate School, 1000 Ljubljana, Slovenia \\ 3 Institute for Hop Research and Brewing, 3310 Žalec, Slovenia; iztok.kosir@ihps.si \\ * Correspondence: jelenagolubovic@gmail.com
}

check for updates

Citation: Golubović, J.B.; Heath, E.; Košir, I.J.; Ogrinc, N.; Potočnik, D.; Strojnik, L.; Heath, D. Differences in the Levels of the Selected

Phytoestrogens and Stable Isotopes in Organic vs. Conventional Hops and Beer. Foods 2021, 10, 1839. https://doi.org/10.3390/foods 10081839

Academic Editors: Pedro Vitoriano de Oliveira and Fernando Barbosa Júnior

Received: 13 June 2021

Accepted: 4 August 2021

Published: 9 August 2021

Publisher's Note: MDPI stays neutral with regard to jurisdictional claims in published maps and institutional affiliations.

Copyright: (c) 2021 by the authors. Licensee MDPI, Basel, Switzerland. This article is an open access article distributed under the terms and conditions of the Creative Commons Attribution (CC BY) license (https:// creativecommons.org/licenses/by/ $4.0 /)$.

\begin{abstract}
Xanthohumol (XN), isoxanthohumol (IX) and 8-prenylnaringenin (8-PN) are important prenylflavonoids present in hops with potential beneficial properties. In this study, we examined differences in the content of XN, IX and 8-PN in hops and beer produced under organic and conventional production regimes. A An ultra-high performance liquid chromatography coupled to tandem mass spectrometry (UHPLC-MS/MS) method for analysing XN, IX and 8-PN in hops and beer was developed and validated, with LOQ ranging from 0.5 to $10 \mathrm{ng} / \mathrm{mL}$. Finally, we examined ${ }^{15} \mathrm{~N} /{ }^{14} \mathrm{~N}$ and ${ }^{12} \mathrm{C} /{ }^{13} \mathrm{C}$ isotope ratios in the hops and beer using isotope ratio mass spectrometry (IRMS). The results show no statistically significant difference in the content of the selected prenylflavonoids between organic and conventionally produced hops and beer-in the whole sample group, as well as between the matched pairs. Stable isotope analysis indicated that only $\delta^{15} \mathrm{~N}$ values are statistically higher in organically produced hops and beer. However, the differentiation according to the type of production could not be made solely based on the $\delta^{15} \mathrm{~N}$ signature, but it could be used to provide supporting evidence.
\end{abstract}

Keywords: beer; hops; organic; liquid chromatography coupled to tandem mass spectrometry (LC-MS/MS); phytoestrogen; stable isotopes; isotope ratio mass spectrometry (IRMS)

\section{Introduction}

Beer production typically includes only four ingredients: water, cereal grain (e.g., barley, wheat or corn), yeast and hops, and it is the female inflorescences (cones) of the hop plant (Humulus lupulus L.) that are used to give beer its characteristic bitterness and floral, fruity or citrus flavours and aroma. Hop consists of many different organic compounds, which can be classified as primary and secondary metabolites based on their role in the plant's life [1]. While primary metabolites have roles associated with nutrition, growth, development and reproduction, secondary metabolites are mainly involved in ecological interactions, including defence and competition [1].

Among the secondary metabolites are polyphenolic compounds such as chalcones and flavanones. Examples include xanthohumol (XN), which is unique to hops, isoxanthohumol (IXN) and 8-prenylnaringenin (8PN), and are of particular interest to the scientific community because of their bioactivity [2,3]. They are members of the prenylflavonoid family of compounds, and contain the common prenyl (3-methyl-1-buten-3-yl) moiety (Figure 1). According to in vitro and in vivo studies, $8 \mathrm{PN}$ is a potent phytoestrogen with a strong binding affinity for estrogen receptors, particularly ERa, with an EC50 equal to $1.5 \mu \mathrm{g} / \mathrm{L}$ or $4.4 \mathrm{nM}$ [3]. Isoxanthohumol, the predominant prenylated flavonoid in beer, is also considered pro-estrogenic since it can be $\mathrm{O}$-demethylated to 8-prenylnaringenin by the action of cytochrome P450 or by intestinal microflora [3]. 


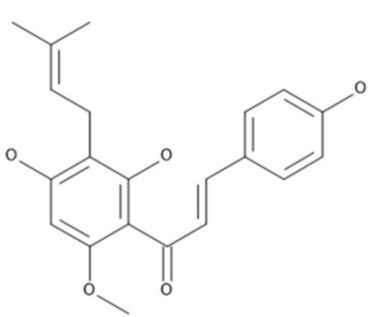

Xanthohumol (XN)

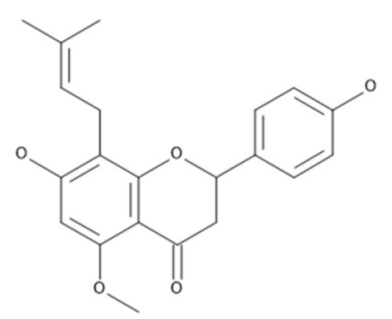

Isoxanthohumol (IXN)

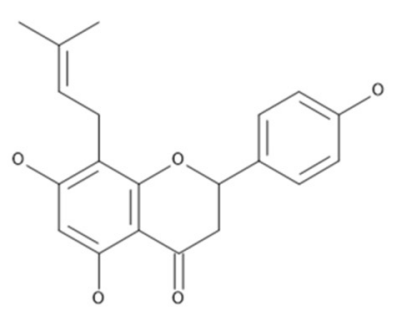

8-Prenylnaringenin (8PN)

Figure 1. Chemical structures of the selected prenylflavonoids.

The estrogenic activity of hops was initially discovered due to female hop-pickers frequently reporting menstrual disturbances, and since then, the question about the estrogenic effect of beer has been asked many times. For example, Sauerwein and Meyer [4] concluded that beer's estrogenic activity is equivalent to only a few $\mu$ g estradiol/L, and an adult would need to drink more than a thousand litres of beer a day to experience adverse feminisation [4]. However, the authors conducted only in vitro studies and did not consider the effects of metabolism, such as the intestinal transformation of IXN to 8PN or how other ingredients affect the metabolism of phytoestrogens [3].

Preclinical animal studies and clinical trials suggest that phytoestrogens may be beneficial in treating climacteric symptoms in perimenopausal women or prevent and treat osteoporosis in postmenopausal women, but more extensive clinical trials are necessary to confirm their benefits [5]. Xanthohumol, the predominant prenylflavonoid in the hop, also shows high antioxidant activity, thereby having a potentially beneficial role in preventing and treating cancer, liver injury, neurodegenerative processes and skin inflammation. However, $\mathrm{XN}$ is only a minor component in beer due to its thermal isomerisation during the brewing process [5-7].

\subsection{Organic Production}

Organic production has many advantages, especially within the ecological and health domain, such as sustainable agriculture, by improving soil quality and fertility, reducing pollution and encouraging agricultural waste recycling. Even though the absence of pesticides and other chemicals contributes to better human health, the question of whether organic crops are more abundant in nutrients remains. Proteomic studies have shown that different proteomes of organically produced crops due to organic farming systems can affect mineral uptake (nutrient utilisation) and metabolic processes in crop plants compared to conventionally produced crops [8].

The assumption that there is a higher content of specific secondary metabolites in organically produced crops than in conventionally produced crops is supported by botanical theory, as De Keukeleire et al., writes "organic plants need to have a much more intricate arsenal of compounds for defence against pests than plants that are protected by a variety of fertilisers and spraying agents" [9]. Studies comparing secondary metabolites in plants grown under different production regimes, for example, using systemic meta-analyses accept [8], reject [10] or partially confirm this hypothesis, i.e., for the defence-related secondary metabolites [11]. Many factors can explain these differences, such as the diversity of compounds and crops, differences in how the results are interpreted, the inclusion of studies published before the EU organic farming regulation was introduced, and the different regulations between Europe and America [12]. Finally, a strong publication bias must not be omitted, i.e., the publication of only affirmative results $[13,14]$.

So far, only one comparative study looks at the content of secondary metabolites, including prenylflavonoids in hops produced organically and conventionally [9]. The authors investigated the synthesis of secondary metabolites ( $\mathrm{XN}$ among them) in three organic and conventionally produced hop varieties: First Gold, Admiral (A) and Wye Challenger. The authors also took into account climate and year of production. Interestingly, First Gold showed enhanced secondary metabolite production when grown organically, 
a finding that was consistent throughout the three harvest seasons. The two other hop varieties, Admiral (A) and Wye Challenger, did not show any uniform pattern and, the results are inconsistent [9]. At present, we are aware of no published study that has looked at the difference in prenylflavonoids between organically and conventionally produced beers. In addition, the ability to distinguish between organic (where at least $95 \%$ of the ingredients must be organically produced) from conventionally produced beer remains a significant challenge. In this regard, prenylflavonoids may act as biological markers of the production regime of hop and beers, especially if combined with the use of stable isotopes.

\subsection{Stable Isotopes}

Among the lighter elements having two or more stable isotopes $(\mathrm{H}, \mathrm{C}, \mathrm{N}, \mathrm{O}, \mathrm{S})$, the stable isotopic composition of nitrogen $\left(\delta^{15} \mathrm{~N}\right.$ values) has been used to differentiate between conventional and organically produced crops [15-18].

In this context, the use of isotopes is based on the fact that synthetic fertilisers, allowed in conventional and integrated agriculture practice, have $\delta^{15} \mathrm{~N}$ values around $0 \%$ [19], but the values of organic manures lie between +2 to $+10 \%$ o $[20,21]$. Thus, organic plant products vary within a range of $\delta^{15} \mathrm{~N}$ values of +0.3 to $+14.6 \%$, while conventional plant products range from negative to positive values, i.e., -4.0 to $+8.7 \%$ [22]. Literature data presented by Mantha et al. [15] indicate that the mean $\delta^{15} \mathrm{~N}$ value of organically grown plants of $7.7 \pm 4.4 \%$ (median $=7.2 \%$ ), while it was $2.8 \pm 2.3 \%$ o (median $=3.0 \%$ o) for plants fertilised inorganically, resulting in a $\delta^{15} \mathrm{~N}_{\text {org-conv }}$ of $4.2 \%$. The stable isotopes of carbon $\left(\delta^{13} \mathrm{C}\right.$ values) can also act as an indicator of crop management practice. During photosynthesis, fertilisation performed in conventional systems involves a higher $\mathrm{N}$ supply to the plant than in organic fertilisation and may modify the $C$ isotope signal due to its effects on stomatal conductance [16]. However, most literature studies are concerned with source identification, and it appears that there are no published studies on the type of production regime, i.e., conventional versus organic beer. For example, $\delta^{13} \mathrm{C}$ values were applied in studies to identify the geographical and botanical source of plants used for beer production $[17,18,23,24]$, rather than management practice discrimination.

In this study, the contents of XN, IXN and 8PN in beer brewed in-house from organic, and conventionally grown hops samples were determined to obtain an insight into the transformation of these prenylflavonoids during the brewing process, i.e., whether the content of the selected prenylflavonoids in hops is reflected in the content of the beer. Given the selected activity of prenylflavonoids, the results could prove beneficial for the botanical dietary supplement industry or beer industry in changing beer consumption habits, i.e., increasing organic beer production and consumption using a higher number of varieties to obtain statistically significant results. Moreover, because of the lack of data regarding the differences between organic and conventional beers, this study set out to use a stable isotope approach $\left(\delta^{15} \mathrm{~N}\right.$ and $\left.\delta^{13} \mathrm{C}\right)$ together with the $\mathrm{XN}$, IXN and $8 \mathrm{PN}$ content to distinguish between conventionally and organically produced hops and conventionally brewed beers and beers labelled as organic on the market, i.e., to act as markers to detect organic production frauds.

\section{Materials and Methods}

\subsection{Chemicals, Solvents and Materials}

Isoxanthohumol ( $\geq 99 \%$ ) was purchased from Sigma Aldrich $\mathrm{GmbH}$, while xanthohumol ( $\geq 98 \%$ ) and 8-prenylnaringenin $(\geq 98 \%)$ were purchased from Enzo Life Sciences, Farmingdale, New York. Eriodyctiol ( $\geq 99 \%)$ and 3,4,2', $4^{\prime}, 6^{\prime}$-pentahydroxychalcone $(\geq 99 \%)$ were purchased from Extrasynthese Lyon, France. Stock solutions of all reference standards were prepared in HPLC grade methanol (J. T. Baker, Deventer, The Netherlands). The same solvent was used for the extraction. Acetonitrile (ACN) was used as the organic part of the mobile phase (LC-MS grade, J. T. Baker, Deventer, Netherlands). Both formic acid (FA) used for SPE (>98\% purity) and FA (LC-MS grade) used as a mobile phase modifier were purchased from Sigma Aldrich (Darmstadt, Germany).MilliQ $(18.2 \mathrm{M} \Omega \cdot \mathrm{cm}$ ) water 
was obtained using a Direct- $Q^{\circledR}$ Water Purification System (Merck, Darmstadt, Germany). Strata-X $33 \mu \mathrm{m}$ polymeric reversed phase cartridges $(60 \mathrm{mg} / 3 \mathrm{~mL})$ were purchased from Phenomenex (Torrance, CA, USA). Before injection into the LC-MS system, the samples were filtered through $0.2 \mu \mathrm{m}$ regenerated cellulose $(\mathrm{RC})$ membrane syringe filters (Phenomenex, Torrance, CA, USA). Hops and beer samples were freeze-dried in a GAMMA 1-16 LSCPlus freeze dryer (Martin Christ Gefrierungstrochnungsanlagen GmbH, Osterode am Harz, Germany).

\subsection{Sampling}

Samples of hop pellets were purchased from Hopfen und mehr, Neukirch, Germany; Hopfen der Welt, Ellingen, Germany; donated by Dr Biendl or collected directly from Slovenian hop growers by the Slovenian Institute of Hop Research and Brewing (SIHRB). Hops samples belonged to 12 hops varieties-each variety represented by an organic and a conventional sample. Among them, 11 organic-conventional hops samples were matched pairs, i.e., the same variety, country of origin and harvest year. The total number of hops samples was 28 (Supplementary material-Table S1).

In-house beer was produced from the samples of hops samples $(n=28)$. The amount of hop added was based on the predetermined content of $\alpha$-acids $-500 \mathrm{mg}$ of $\alpha$-acids in $1 \mathrm{~L}$ of wort. Beers were fermented using a bottom-fermented yeast strain SafLager W-34/70 (Fermentis, France) at $12{ }^{\circ} \mathrm{C}$ for five days to produce lager style beer. A blank matrix or "zero beer" was brewed according to the same procedure, only without the hops.

Commercial beer samples ( $n=27$, Supplementary material-Table S2) were purchased in Slovenia and Belgian stores. In this case, 15 different beers labelled as organic were matched with 12 conventional beers regarding style and alcohol content $( \pm 1 \%)$.

\subsection{Sample Preparation}

Hop pellets were ground in a mortar and sieved through a $0.5 \mu \mathrm{m}$ sieve (No 35). A small quantity $(0.1 \mathrm{~g})$ of the sieved sample was then weighed in a falcon tube and extracted in $10 \mathrm{~mL}$ of methanol by sonication for $15 \mathrm{~min}$ at room temperature. After centrifugation (5000 rpm for $5 \mathrm{~min}$ ), the supernatants were filtered through a syringe filter and diluted in the injection solvent $(0.1 \% \mathrm{FA}$ in water/ACN, $70: 30, v / v)$ in vials. The water content in the sieved samples was determined after heating $2 \mathrm{~g}$ of the sieved hops at $105^{\circ} \mathrm{C}$ for $1 \mathrm{~h}$.

\subsection{Solid-Phase Extraction}

Sample preparation began by extensive degassing the beer with consecutive hand mixing and sonication (for about an hour). The selected prenylflavonoids- $-\mathrm{XN}, \mathrm{IXN}$ and 8-PN, were extracted using solid-phase extraction (SPE) with Strata-X $33 \mu \mathrm{m}$ polymeric reversed phase cartridge. The method is shown schematically in the Supplementary material-Figure S1. The cartridges were conditioned with $1 \mathrm{~mL}$ of $2 \%$ formic acid in water (Milli-Q) and equilibrated with $2 \mathrm{~mL}$ of water. Next, $950 \mathrm{~mL}$ of beer samples and $50 \mathrm{~mL}$ of methanol was loaded for the samples, while $950 \mathrm{~mL}$ of zero beer and $50 \mathrm{~mL}$ of spiked methanol was loaded for calibration and QCs. The washing step consisted of $2 \mathrm{~mL}$ of $40 \%$ methanol in water. After cartridges drying under vacuum ( $>10^{\prime \prime} \mathrm{Hg}$, approx. $30 \mathrm{~min}$ ), the analytes were eluted with $1 \mathrm{~mL}$ of $2 \%$ formic acid in methanol. The eluted samples were dried under nitrogen gas at $40{ }^{\circ} \mathrm{C}$ and reconstituted in the injection solvent, i.e., $1 \mathrm{~mL}$ of $0.1 \%$ formic acid in a water-acetonitrile mixture $(30: 70 \mathrm{v} / \mathrm{v})$.

\subsection{LC-MS/MS Method Development and Validation}

The samples were analysed using liquid chromatography coupled to a tandem mass spectrometer system (LC-MS/MS) consisting of a Shimadzu Nexera X2 UHPLC (Kyoto, Japan) and QTRAP ${ }^{\circledR} 4500$ (Sciex, Framingham, MA, USA). Separation was achieved at $30^{\circ} \mathrm{C}$ using an Ascentis ${ }^{\circledR}$ Express C-18 column $(50 \times 2.1 \mathrm{~mm}, 1.7 \mu \mathrm{m})$ (Supelco, Bellefonte, PA, USA). The injection volume was $5 \mu \mathrm{L}$. The mobile phases consisted of $0.1 \%$ FA (A) and ACN (B). The gradient started with 30\% B and increased to $70 \%$ in $1.5 \mathrm{~min}$, followed by 
isocratic flow for $2.5 \mathrm{~min}$, then fast return to initial conditions (30\% B) in $0.1 \mathrm{~min}$, and a final equilibration phase of $0.9 \mathrm{~min}$. The total run time was $5 \mathrm{~min}$, and the flow rate was $0.3 \mathrm{~mL} / \mathrm{min}$. The first $1.4 \mathrm{~min}$ of eluting solvent was sent to waste via the divert valve. The MS analyser was operated under electrospray ionisation (ESI) in negative mode with the following settings: curtain gas: 35 psi; source temperature: $200{ }^{\circ} \mathrm{C}$; ion spray voltage: $-4500 \mathrm{~V}$; ion source gas one: $20 \mathrm{psi}$; and ion source gas two: 20 psi. Analyte quantification was performed in multiple reaction monitoring (MRM) mode using Analyst v1.6.3 software. All samples were injected in duplicate.

The matrix effect $(\mathrm{ME})$ and extraction efficiency $(\mathrm{EE})$ were calculated by applying the following equations:

$$
\begin{gathered}
\operatorname{ME}(\%)=\frac{\text { Slope }_{\text {spiked matrix extract }}}{\text { Slope }_{\text {solvent }}} \times 100 \\
\text { Extraction efficiency }(\%)=\frac{\text { Slope }_{\text {pre-extraction spiked matrix }}}{\text { Slope }_{\text {spiked matrix extract }}} \times 100
\end{gathered}
$$

Calibration standards were prepared in duplicate by spiking matrices with a mixture of analytes at eight concentration levels: $0.5,1,5,10,50,100,500$ and $1000 \mathrm{ng} / \mathrm{mL}$. The validation matrix for hops was a hops pool, while the validation matrix for beer was zero beer. The method's accuracy was determined by back-calculation using the regression equation (Eq. 4) and expressed as accuracy bias. The acceptable bias for the quality control (QC) of low, middle and higher concentration levels obtained for three replicates for each QC level was $<15 \%$. The low QC was considered the limit of quantification (LOQ).

$$
\text { Bias }(\%)=\left(1-\frac{\text { Calculated concentration }}{\text { Theoretical concentration }}\right) \times 100
$$

Precision was evaluated by performing a repeat analysis $(n=6)$ as intraday precision and over three days to estimate inter-day precision at the middle concentration level. Relative standard deviations were below $15 \%$.

\subsection{Isotope Ratio Mass Spectrometry (IRMS)}

In bulk hops and beer samples (freeze-dried), the $\delta^{13} \mathrm{C}$ and $\delta^{15} \mathrm{~N}$ values were determined using an IsoPrime100 isotope ratio mass spectrometer (IsoPrime, Cheadle, Hulme, UK) connected to a Vario PYRO Cube OH/CNS Pyrolyser/Elemental Analyzer (IsoPrime, Cheadle, Hulme, UK). Briefly, $2.5 \mathrm{mg}$ of hop sample or $5 \mathrm{mg}$ of beer samples were weighed into a tin capsule, closed with tweezers and put in the automatic sampler of the elemental analyser.

Stable isotope data are reported as deviations from an international standard and are given in the $\delta$-notation (\%o) using the general formula:

$$
\delta^{*} X=\left[\frac{\left(\frac{{ }^{*} X}{X}\right)_{\text {sample }}}{\left(\frac{{ }^{*} X}{X}\right)_{\text {standard }}}-1\right] \times 100
$$

where $\delta^{*} \mathrm{X}$ refers to $\delta^{13} \mathrm{C}, \delta^{15} \mathrm{~N}$, while ${ }^{*} \mathrm{X} / \mathrm{X}$ are the ratios ${ }^{13} \mathrm{C} /{ }^{12} \mathrm{C},{ }^{15} \mathrm{~N} /{ }^{14} \mathrm{~N}$ of the sample, and an international reference standard. Analyses were calibrated against the following international standards: USGS64 (glycine, $\delta^{13} \mathrm{C}=-40.81 \pm 0.04 \%$ ) and USGS62 (caffeine, $\delta^{13} \mathrm{C}=-14.79 \pm 0.04 \%$ ) and USGS62 (caffeine, $\delta^{15} \mathrm{~N}=20.17 \pm 0.06 \%$ ) and IAEA-600 (caffeine, $\delta^{15} \mathrm{~N}$ values of $1.02 \pm 0.05 \%$ ). Other control reference materials were IAEA-600 caffeine with $\delta^{13} \mathrm{C}$ values of $-27.73 \pm 0.04 \%$ and CRP-IAEA casein with $\delta^{13} \mathrm{C}=-20.3 \pm 0.09 \%$ for carbon and USGS64 (glycine) with $\delta^{15} \mathrm{~N}$ values of $1.76 \pm 0.06 \%$ and CRP-IAEA casein with $\delta^{15} \mathrm{~N}$ values of $5.62 \pm 0.19 \%$ for nitrogen. The $\delta^{13} \mathrm{C}$ values are reported relative to the V-PDB (Vienna-Pee Dee Belemnite) standard, while $\delta^{15} \mathrm{~N}$ values 
are given relative to the V-CDT (Vienna Cañon Diablo Troilite) and AIR. Each sample was analysed in triplicate, and the means were calculated. The reproducibility for $\delta^{13} \mathrm{C}$ was $\pm 0.2 \%$ and $\pm 0.3 \%$ or for $\delta^{15} \mathrm{~N}$.

\subsection{Statistical Evaluation of the Data}

Simple statistical analyses were carried out to check significant differences in measured parameters between conventionally and organically produced hops and beer using a Student t-test. Moreover, orthogonal projections to latent structures discriminant analysis (OPLS-DA) were performed on all the data to identify the most relevant parameters for discriminating hops and beer samples according to the production regime (organic/conventional).

\section{Results and Discussion}

\subsection{Method Development and Validation}

Sample preparation and analysis were based on literature methods $[25,26]$ and optimised for our application. Supplementary material-Table S3 gives retention times and MRM parameters. Although several published methods $[25,27,28]$ suggest filtering the samples using nylon filters, we found that these filters adsorbed the compounds of interest and that RC membrane filters were a better option.

Since there is no guideline for specifically analysing natural products in plants or foodstuffs," our validation approach was based on AOAC [29], Eurachem guidelines [30], and other guidelines for analysing foodstuffs [31,32]. Different calibration approaches were tested, including solvent calibration (with and without an internal standard), matrixmatched calibration and standard addition calibration. Since stable isotope-labelled internal standards are not commercially available, structural analogues (surrogate standards), which are not present in the analysed samples (beer and hops), were tested as internal standards during the development stage. Accordingly, the flavanone eriodyctiol its chalcone analogue $3,4,2^{\prime}, 4^{\prime}, 6^{\prime}$-pentahydroxychalcone were tested as potential internal standards. Since there was no benefit in accuracy and precision from using these compounds as internal standards, the idea was discarded, while matrix-matched calibration was ruled out for hops because they contained the selected compounds. Therefore, standard addition calibration was used for the quantitative analysis of hops. Matrix-matched calibration, whereby the blank matrix was spiked before the extraction (also called modified matrix-matched calibration), was selected for beer, whereby zero beer was used as a blank matrix. The matrix was spiked before the extraction to compensate for the low and variable extraction efficiencies in both cases.

The validation results are presented in the Supplementary material-Table S4 and Table S5, respectively.

\subsection{Hops and Beer Samples}

The content of the selected analytes in hops samples ( $\mu \mathrm{g}$ per gram of dry hops) are presented in Table 1. Since the samples contained a significant amount of water, concentrations were expressed on a dry weight basis. The water content in the sieved samples was determined after heating $2 \mathrm{~g}$ of the sieved hops at $105^{\circ} \mathrm{C}$ for $1 \mathrm{~h}$ and is presented in Table 1. 
Table 1. Stable isotope data and results of xanthohumol (XN), isoxanthohumol (IXN) and 8-prenylnaringenin (8PN) analysis of hop samples and in-house beer $(n=2)$.

\begin{tabular}{|c|c|c|c|c|c|c|c|c|c|c|c|}
\hline \multirow[b]{2}{*}{ Label } & \multirow[b]{2}{*}{ Type } & \multirow{2}{*}{$\begin{array}{c}\delta^{15} N \\
(\% 0)\end{array}$} & \multirow{2}{*}{$\begin{array}{c}\delta^{13} \mathrm{C} \\
(\%)\end{array}$} & \multirow{2}{*}{$\begin{array}{c}\text { Water } \\
\text { Content } \\
(\%)\end{array}$} & \multicolumn{3}{|c|}{ Hops } & \multicolumn{4}{|c|}{ Beer } \\
\hline & & & & & $\begin{array}{c}\text { IXN } \\
(\mu \mathrm{g} / \mathrm{g})\end{array}$ & $\begin{array}{c}8 P N \\
(\mu g / g)\end{array}$ & $\begin{array}{c}\text { XN } \\
(\mu g / g)\end{array}$ & $\begin{array}{l}\text { Weighed } \\
\text { hops (g) }\end{array}$ & $\begin{array}{c}\text { IXN } \\
(\mathrm{ng} / \mathrm{mL})\end{array}$ & $\begin{array}{c}8 P N \\
(\mathrm{ng} / \mathrm{mL})\end{array}$ & $\begin{array}{c}\mathrm{XN} \\
(\mu \mathrm{g} / \mathrm{g})\end{array}$ \\
\hline H1 & organic & 7.9 & -27.6 & 8.1 & 2.2 & 9.6 & 378 & 16.5 & 1030 & 19.8 & 263 \\
\hline $\mathrm{H} 2$ & conventional & 6.0 & -27.1 & 7.0 & 1.5 & 11.2 & 345 & 24 & 1410 & 23.0 & 538 \\
\hline H3 & organic & 7.7 & -27.1 & 8.0 & 1.1 & 4.7 & 173 & 27 & 553 & 17.2 & 296 \\
\hline $\mathrm{H} 4$ & conventional & 9.5 & -27.1 & 9.0 & 1.2 & 4.9 & 188 & 35 & 671 & 18.4 & 363 \\
\hline H5 & organic & 6.6 & -27.2 & 8.1 & 1.3 & 6.1 & 287 & 15 & 718 & 14.9 & 198 \\
\hline H6 & conventional & 7.5 & -27.2 & 8.0 & 1.0 & 5.9 & 232 & 19 & 811 & 19.5 & 344 \\
\hline H7 & organic & 6.6 & -27.7 & 8.4 & 1.9 & 13.5 & 511 & 5.8 & 1850 & 25.8 & 188 \\
\hline H8 & conventional & 6.2 & -27.5 & 8.0 & 1.6 & 15.9 & 491 & 8.5 & 1120 & 19.5 & 283 \\
\hline H9 & organic & 5.3 & -26.6 & 6.5 & 0.6 & 10.9 & 407 & 5.6 & 517 & 3.8 & 102 \\
\hline H10 & conventional & 8.1 & -26.1 & 7.5 & 0.6 & 9.6 & 445 & 4.3 & 621 & 6.6 & 71.2 \\
\hline H11 & organic & 10.3 & -26.9 & 8.7 & 1.1 & 7.1 & 199 & 27 & 644 & 8.2 & 79.2 \\
\hline H12 & conventional & 6.3 & -26.6 & 8.1 & 1.2 & 7.9 & 264 & 21 & 1040 & 13.2 & 81.2 \\
\hline H13 & organic & 7.2 & -25.5 & 8.0 & 1.3 & 11.4 & 376 & 18 & 1470 & 21.5 & 97.4 \\
\hline H14 & conventional & 4.8 & -27.1 & 7.5 & 1.6 & 13.4 & 463 & 7.8 & 1130 & 16.9 & 66.9 \\
\hline H15 & organic & 7.5 & -26.2 & 5.9 & 1.5 & 18.6 & 555 & 4.9 & 1290 & 14.2 & 38.6 \\
\hline H16 & conventional & 5.9 & -26.8 & 5.9 & 1.0 & 9.4 & 384 & 8.5 & 1170 & 16.5 & 84.8 \\
\hline H19 & organic & 8.6 & -26.2 & 9.9 & 1.3 & 8.1 & 242 & 11 & 570 & 11.5 & 44.4 \\
\hline $\mathrm{H} 20$ & conventional & 5.5 & -26.4 & 8.0 & 1.2 & 10.3 & 314 & 9.6 & 617 & 13.4 & 65.6 \\
\hline $\mathrm{H} 21$ & organic & 10.9 & -28.1 & 9.5 & 1.3 & 11.0 & 341 & 12 & 858 & 13.7 & 91.1 \\
\hline $\mathrm{H} 22$ & conventional & 5.9 & -27.3 & 8.5 & 1.3 & 13.2 & 366 & 12 & 987 & 16.0 & 129 \\
\hline $\mathrm{H} 23$ & organic & 7.9 & -26.9 & 8.5 & 1.5 & 11.9 & 327.3 & 7.7 & 896 & 17.5 & 67.1 \\
\hline $\mathrm{H} 24$ & conventional & 6.4 & -27.0 & 8.0 & 1.9 & 19.6 & 480 & 8.2 & 1114.1 & 19.2 & 64.4 \\
\hline $\mathrm{H} 25$ & organic & 6.5 & -25.8 & 11.4 & 1.1 & 8.3 & 460 & 11 & 595.6 & 6.5 & 54.5 \\
\hline H26 & conventional & 5.7 & -25.6 & 7.0 & 1.5 & 24.8 & 301 & 5.2 & 196.1 & 5.0 & 76.0 \\
\hline $\mathrm{H} 27$ & organic & 5.4 & -25.6 & 21.6 & 0.8 & 4.2 & 87.4 & 71 & 984.5 & 16.7 & 32.5 \\
\hline $\mathrm{H} 28$ & conventional & 5.4 & -25.1 & 8.5 & 0.9 & 2.5 & 230 & 16 & 964.9 & 16.3 & 29.8 \\
\hline
\end{tabular}

The student t-test revealed no statistical difference in the content of the selected prenylflavonoids between the two groups: $p$-values were $0.3,1$ and 0.9 for IXN, 8PN and $\mathrm{XN}$, respectively. A paired sample sign test comparing the differences in matched pairs also revealed no statistical difference, with $p$-values of $0.11,0.75$ and 0.75 for IXN, 8PN and $\mathrm{XN}$, respectively (Figure 2a). Further, from the principal component analysis (PCA), it was impossible to discriminate between conventional and organic hop based on the prenylflavonoid content (Figure 2b). Figure 2c plots the relative contents of IXN, 8PN and $\mathrm{XN}$. The relative contents were calculated as the amount of analyte in the sample/average amount of analyte in the sample group and were carried out to gain insight into the synthesis of the examined compounds in a sample, i.e., their relative ratios. Relative contents were chosen over their absolute contents in order to present the data on the same graph. The result revealed no strict proportionality in the compounds, i.e., transformations and metabolism, depend on many factors. The average concentrations were $340 \pm 116 \mu \mathrm{g} / \mathrm{g}$, $10.5 \pm 5.0 \mu \mathrm{g} / \mathrm{g}$ and $1.3 \pm 0.4 \mu \mathrm{g} / \mathrm{g}$ for XN, IXN and 8PN $(n=28)$, respectively. These results for the whole group of hop samples agrees with the published data. For example, Stevens et al. [25] obtained $478 \mu \mathrm{g} / \mathrm{g}, 8 \mu \mathrm{g} / \mathrm{g}$ and $2.1 \mu \mathrm{g} / \mathrm{g}$ for XN, IXN and 8PN $(n=1)$, respectively, while Magalhães et al. [28] reported $620 \mu \mathrm{g} / \mathrm{g}$ of XN, and IXN levels below the LOD $(12 \mu \mathrm{g} / \mathrm{g})$ in hop pellets samples $(n=1)$. De Keukeleire et al. [9] reported a XN content of $450 \pm 215 \mu \mathrm{g} / \mathrm{g}$. 


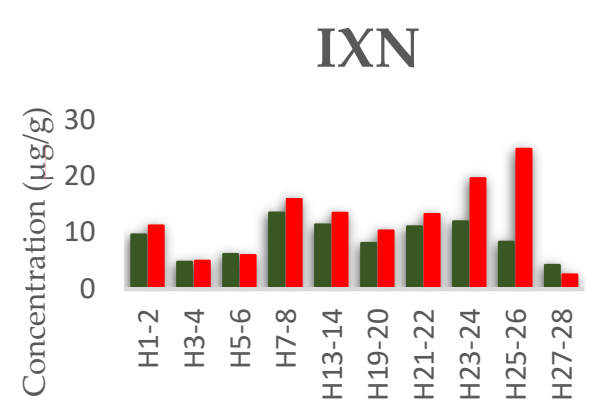

凹 org $\mathbf{D}$ conv

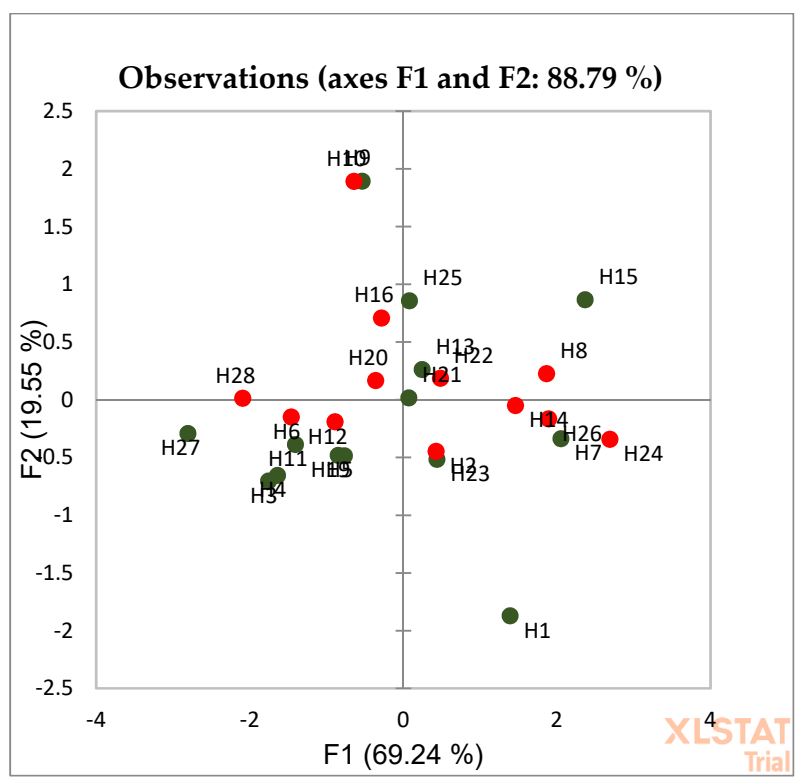

(b)

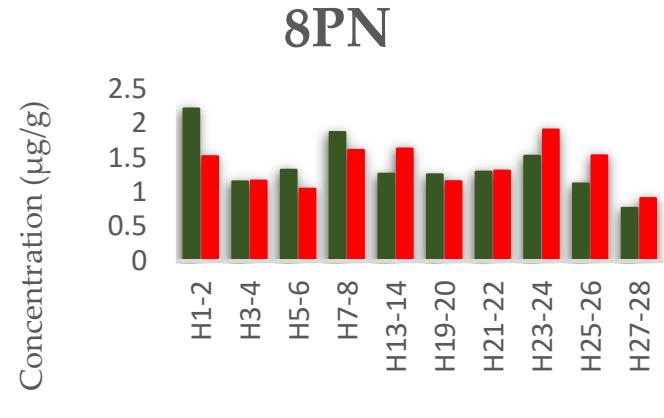

$\boldsymbol{\square} \operatorname{org}$ conv

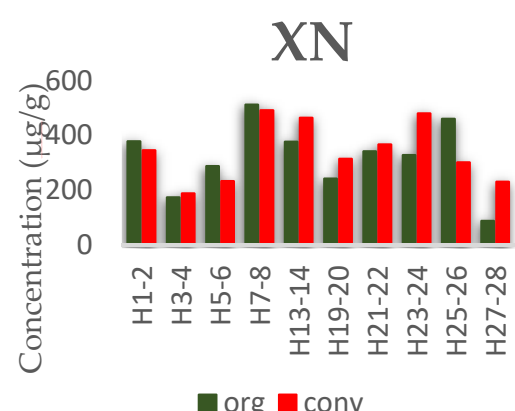

- org [ conv

(a)

Relative content

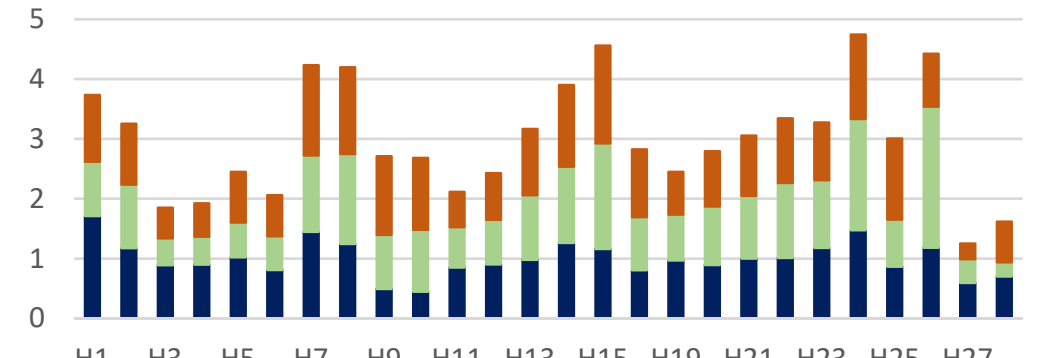

-8PN $=$ IXN $=X N$

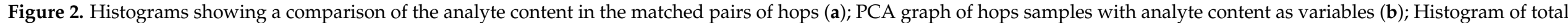
contents of the analytes in hops samples expressed as the sum of relative contents to the average level of a single analyte in the whole group (c). 
Table 1 gives the concentrations of the prenylflavonoids in the in-house beer samples. The quantity of hop used for beer production was chosen according to its $\alpha$-acids content (Supplementary material-Table S1). The total amount of the selected compounds in beer was expressed as a sum of the single analyte concentrations divided by the quantity of hop used in the brewing process (per gram of hops). The total content of IXN, 8PN and XN is expressed as the summed concentrations of the selected compounds in the whole hop samples, i.e., sample weight that includes water. The coefficients of determination $\left(R^{2}\right)$ in the total contents between hops and beer were $0.643,0.662$ and 0.853 for the whole group, organic samples and conventional samples, respectively (Figure 3). These findings suggest a linear correlation exists between the total content of the selected prenylflavonoids. The weaker correlations are likely due to metabolites with similar structures that play a role in transforming prenylflavonoids during the brewing process, which were not included in the study since they have no physiological activity. The weak correlation observed in organic samples likely reflects the diversity of similarly structured metabolites formed under less controlled conditions.

Total content - organic samples

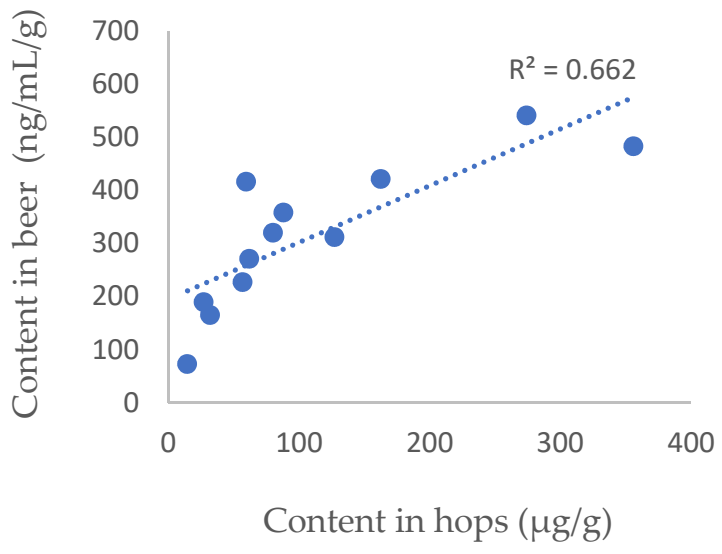

(a)
Total content - conventional samples

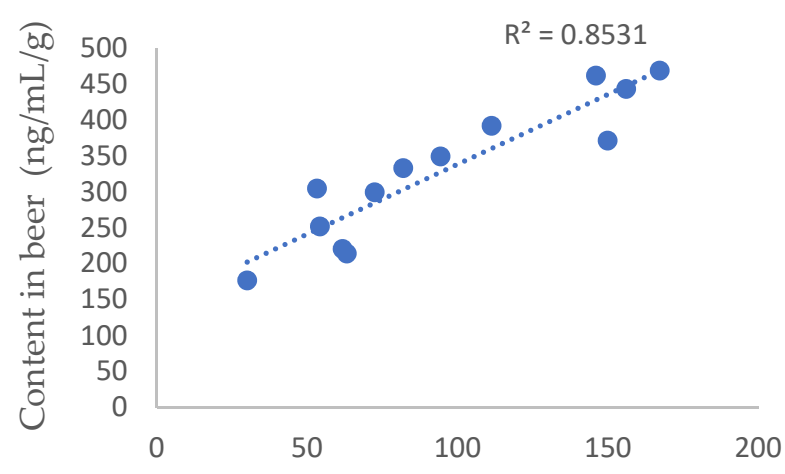

Content in hops $(\mu \mathrm{g} / \mathrm{g})$

(b)

Total content - all samples

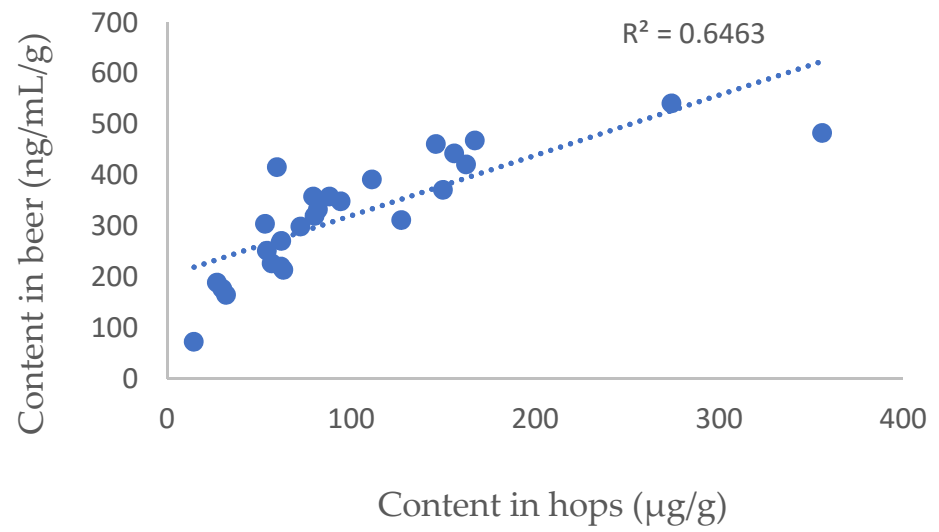

(c)

Figure 3. The total content of the selected prenylflavonoids in hops plotted against the total content of selected prenylflavonoids in beer in the (a), organic samples (a), conventional samples $(\mathbf{b})$ and whole sample group (c).

The $\delta^{15} \mathrm{~N}$ and $\delta^{13} \mathrm{C}$ values in the hop samples are presented in Table 1 . The $\delta^{15} \mathrm{~N}$ values ranged from 5.3 to $10.9 \%$ for organic hops and are statistically higher $(p=0.027)$ than 
conventional ones (from 4.8 to $9.5 \%$ ). It is difficult to explain the $\delta^{15} \mathrm{~N}$ values in hops since the processes and the fractionation influencing the $\mathrm{N}$ cycle is not well understood and hop $\mathrm{N}$ requirements can be satisfied from several sources. In addition to commercial fertiliser, soil organic matter, manure, cover crops and returned hop vines can supply substantial $\mathrm{N}$ for hop production and influence the $\delta^{15} \mathrm{~N}$ values. It is interesting to note that the highest $\delta^{15} \mathrm{~N}$ values in EU hops originate from the Czech Republic, one of the largest hop producers in the world (26). No statistically significant difference was observed in the $\delta^{13} \mathrm{C}$ values (average $-26.7 \pm 0.8 \%$ ) between conventionally and organically produced hops. However, $\delta^{15} \mathrm{~N}$ values in European samples were lower than the organically produced hops [24].

\subsection{Commercial Beer Samples}

The levels of IXN, 8PN and XN in commercial beer samples are presented in Table 2. Student $\mathrm{t}$-tests show no statistical difference in their content between the two groups, with $p$-values of $0.19(\mathrm{IXN}), 0.38(8 \mathrm{PN})$ and $0.33(\mathrm{XN})$. The paired-sample sign test, comparing the differences in matched pairs, revealed no statistical difference with $p$-values (IXN $=0.6$, $8 \mathrm{PN}=0.1$ and $\mathrm{XN}=1$, Figure $4 \mathrm{a}$ ). Using the $\mathrm{IXN}, 8 \mathrm{PN}$ and $\mathrm{XN}$ content as a variable in the PCA did not discriminate between conventionally and organically grown hops (Figure $4 \mathrm{~b}$ ). Again, the levels of IXN, $8 \mathrm{PN}$ and $\mathrm{XN}$ in the whole group of beer samples $(n=27)$ agree with the published results with average concentrations of $0.023 \pm 0.013 \mu \mathrm{g} / \mathrm{L}$, $0.963 \pm 0.593 \mu \mathrm{g} / \mathrm{L}$ and $0.016 \pm 0.006 \mu \mathrm{g} / \mathrm{L}$. Stevens et al. [25], investigating different beer styles and countries of production, obtained $0.023 \pm 0.019 \mu \mathrm{g} / \mathrm{L}, 1.02 \pm 0.98 \mu \mathrm{g} / \mathrm{L}$ and $0.049 \pm 0.071 \mu \mathrm{g} / \mathrm{L}$ for $\mathrm{XN}, \mathrm{IXN}$ and $8 \mathrm{PN}$, respectively $(n=11)$.

The $\delta^{15} \mathrm{~N}$ and $\delta^{13} \mathrm{C}$ values for commercial beer samples are presented in Table 2. The $\delta^{15} \mathrm{~N}$ values for beers declared organic range from 3.4 to $7.4 \%$ and are statistically higher $(p=0.007)$ than non-organic beers ( 2.9 to $4.9 \%)$. However, $\delta^{15} \mathrm{~N}$ values are lower than those observed in organic hop samples. This value was expected since the hop represents only $1 \%$ of the beer components. Further, although the $\delta^{15} \mathrm{~N}$ values were significantly higher in organically produced beer, it would be difficult to confirm the production regime based only on $\delta^{15} \mathrm{~N}$ values since the conventional and organic beer data overlap. The $\delta^{13} \mathrm{C}$ values show no statistically significant difference between organic and non-organic beer, but the average $\delta^{13} \mathrm{C}$ value of $-27.5 \pm 0.6 \%$ indicate only C 3 carbon. This finding is consistent with the previous studies performed on European beer. For example, Brooks et al. [17] found that European beer had an average $\delta^{13} \mathrm{C}$ value of $-25.6 \pm 1.5 \%$, indicating that only malt, a C3-source, was used during brewing as opposed to the presence of a C4-source in their composition, such as maise, which is typical for South and North American and Asian beers [18].

All data from the hop and beer were further statistically evaluated using OPLS-DA. The results are presented in Figure 5. In the OPLS-DA models, the leave-one-out was automatically used as cross-validation to obtain the misclassification result. The accuracy (CA), precision, recall and F1-score were calculated and presented for each model. The classification rate of these OPLS-DA models was between $77 \%$ and $80 \%$ for hops and beer, respectively, indicating a good separation between organic and conventional hops and beer despite the low number of samples. The variable importance in the projection (VIP) values of OPLS-DA models are also presented (Figure 5). A VIP value of more than 1.0 revealed that the corresponding variable was important in discriminating the production practice. In both cases, the $\delta^{15} \mathrm{~N}$ value is the main discriminating parameter, while for beer, also IXN seems to be important. The evaluation of results needs to be confirmed by including a higher number of samples. 
Table 2. Stable isotope data and results of the xanthohumol (XN), isoxanthohumol (IXN) and 8-prenylnaringenin $(8 \mathrm{PN})$ analysis in commercial beer samples $(n=2)$.

\begin{tabular}{|c|c|c|c|c|c|c|}
\hline Label & Type & $\delta^{15} \mathrm{~N}(\%$ o) & $\delta^{13} \mathrm{C}(\%)$ & IXN ( $\mu \mathrm{g} / \mathrm{L})$ & $8 \mathrm{PN}(\mu \mathrm{g} / \mathrm{L})$ & $X N(\mu g / L)$ \\
\hline UO1 & organic & 3.4 & -27.2 & 1.834 & 0.010 & 0.027 \\
\hline UO2 & organic & 3.6 & -27.0 & 1.549 & 0.012 & 0.032 \\
\hline UO3 & organic & 4.0 & -27.4 & 0.727 & 0.020 & 0.020 \\
\hline UO4 & organic & 5.1 & -28.3 & 1.096 & 0.012 & 0.018 \\
\hline UO5 & organic & 5.2 & -25.9 & 0.676 & 0.022 & 0.014 \\
\hline UO6 & organic & 4.9 & -28.4 & 0.856 & 0.011 & 0.017 \\
\hline UO7 & organic & 4.2 & -27.4 & 0.894 & 0.016 & 0.036 \\
\hline UO8 & organic & 5.1 & -27.2 & 0.662 & 0.013 & 0.026 \\
\hline UO9 & organic & 4.0 & -27.9 & 0.907 & 0.016 & 0.013 \\
\hline UO10 & organic & 4.7 & -27.9 & 0.754 & 0.012 & 0.012 \\
\hline UO11 & organic & 7.4 & -26.7 & 1.35 & 0.022 & 0.019 \\
\hline UO12 & organic & 3.3 & -27.9 & 0.705 & 0.015 & 0.023 \\
\hline UO13 & organic & 4.9 & -28.4 & 1.11 & 0.023 & 0.017 \\
\hline UO14 & organic & 4.3 & -27.9 & 1.64 & 0.022 & 0.042 \\
\hline UO15 & organic & 3.9 & -27.9 & 1.20 & 0.012 & 0.015 \\
\hline UK3 & conventional & 4.1 & -27.2 & 0.716 & 0.019 & 0.060 \\
\hline UK7 & conventional & 2.9 & -28.3 & 0.492 & 0.006 & 0.012 \\
\hline UK8 & conventional & 4.6 & -28.4 & 3.11 & 0.014 & 0.025 \\
\hline UK9 & conventional & 3.6 & -27.4 & 0.740 & 0.017 & 0.029 \\
\hline UK10 & conventional & 3.3 & -27.0 & 0.632 & 0.018 & 0.031 \\
\hline UK11 & conventional & 2.4 & -27.4 & 0.221 & 0.006 & 0.006 \\
\hline UK12 & conventional & 3.3 & -26.9 & 1.31 & 0.023 & 0.037 \\
\hline UK13 & conventional & 3.4 & -27.3 & 0.155 & 0.003 & 0.007 \\
\hline UK14 & conventional & 3.2 & -27.2 & 0.205 & 0.007 & 0.009 \\
\hline UK15 & conventional & 4.4 & -27.2 & 0.713 & 0.013 & 0.018 \\
\hline UK16 & conventional & 4.9 & -22.6 & 0.486 & 0.022 & 0.050 \\
\hline UK17 & conventional & 4.3 & -27.5 & 1.24 & 0.032 & 0.014 \\
\hline
\end{tabular}



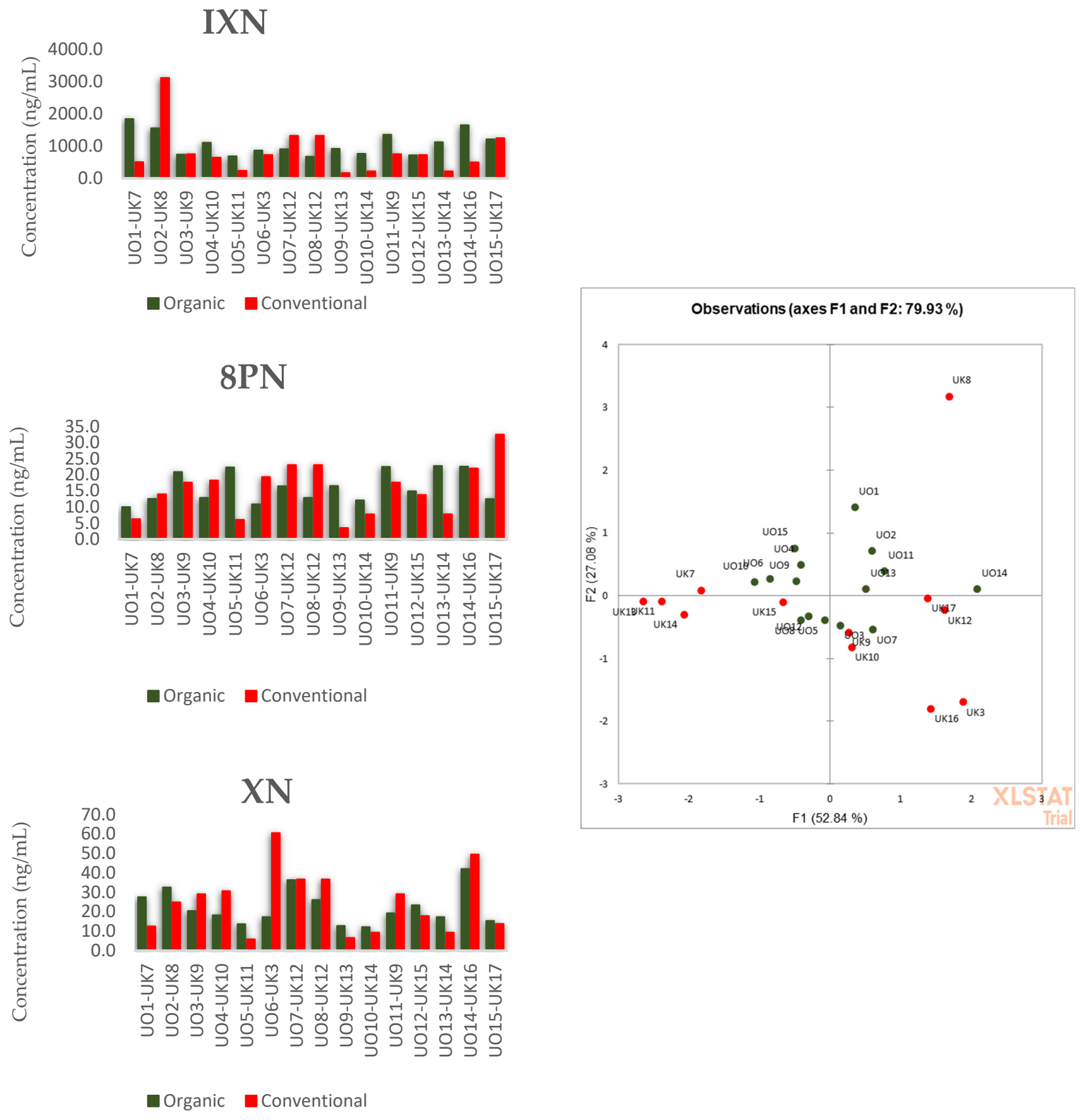

(a)

(b)

Figure 4. Comparison of the analyte content in the matched pairs of commercial beers (a); PCA graph of commercial beer samples with analytes contents as variables (b). 

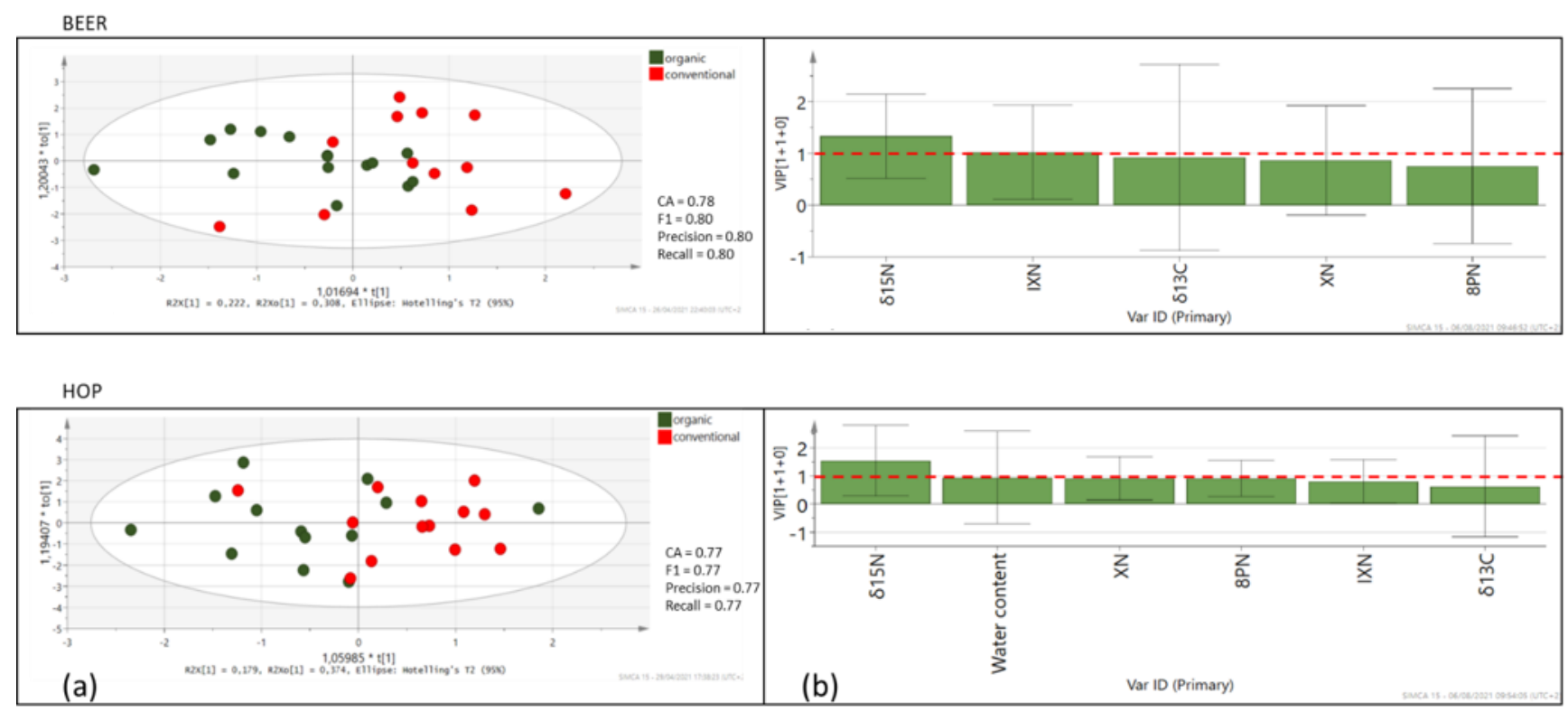

Figure 5. OPLS-DA score plots (a) with VIP values (b) in the pairwise comparison between different production practices for beer and hops. The red-dotted line at VIP $=1.0$ indicates criteria for the identification of the most important model variable.

\section{Conclusions}

In conclusion, an LC-MS/MS method for analysing XN, IXN and 8PNwas developed and validated. Even though higher amounts of secondary metabolites in organically produced crops are reported in the literature, it was not the case in this study regarding hops. In addition, PCA based on the determined prenylflavonoid levels could not distinguish between organically and conventionally produced hops and beer. Instead, more likely, variety plays a more significant role in the synthesis of specific secondary metabolites than the agricultural management practice. In addition, the transformation of $\mathrm{XN}$ to IXN seems to be more complicated than schematically presented in the literature. Finally, measuring the level of XN, IXN and 8PN did not prove sufficient to detect mislabelling and other frauds. However, the $\delta^{15} \mathrm{~N}$ values confirm previous findings that show statistically higher values in organic hops and beer. However, there is a potential overlap between the $\delta^{15} \mathrm{~N}$ signatures, and it would not be easy to check the production type based solely on $\delta^{15} \mathrm{~N}$ values. Despite this, separation could be further improved using OPLS-DA to give an overall correct classification rate of $77 \%$. $\delta^{15} \mathrm{~N}$ values and IXN were defined as the most promising parameters for differentiation between organically and non-organically produced beer. Even though obtained results are promising, further improvement of the methodology is needed, including analysing more samples from different years of production.

Supplementary Materials: The following are available online at https:/ / www.mdpi.com/article/10 .3390 /foods10081839/s1, Figure S1: SPE protocol for sample preparation of beer samples, Table S1: Hops samples, Table S2: Beer samples, Table S3: Parameters of the LC-MS/MS method, Table S4: Validation data for hops, Table S5: Validation data for beer.

Author Contributions: Conceptualisation, J.B.G., E.H., N.O. and D.H.; data curation, J.B.G.; formal analysis, J.B.G., I.J.K., N.O., D.P. and L.S.; funding acquisition, E.H. and D.H.; investigation, J.B.G., N.O., D.P. and L.S.; methodology, J.B.G., I.J.K., N.O. and D.H.; project administration, E.H. and D.H.; supervision, E.H. and D.H.; validation, J.B.G.; visualisation, J.B.G., N.O., D.P. and L.S.; writingoriginal draft, J.B.G. and N.O.; writing-review and editing, E.H. and D.H. All authors have read and agreed to the published version of the manuscript.

Funding: This work was financially supported by the Slovenian Research Agency (Program group P1-0143), ISO-FOOD project (Era Chair for Isotope Techniques in Food Quality, Safety and Traceability, 
Grant 621329) and the MASSTWIN project that has received funding from the European Union's Horizon 2020 research and innovation programme under grant agreement no. 692241.

Acknowledgments: The authors kindly thank SM. Biendl, Hopsteiner GmbH, Mainburg, Germany, for donating the hop samples.

Conflicts of Interest: The authors declare that there is no conflict of interest regarding the publication of this article.

\section{References}

1. Erb, M.; Kliebenstein, D.J. Plant Secondary Metabolites as Defenses, Regulators, and Primary Metabolites: The Blurred Functional Trichotomy. Plant Physiol. 2020, 184, 39-52. [CrossRef] [PubMed]

2. Liu, M.; Yin, H.; Liu, G.; Dong, J.; Qian, Z.; Miao, J. Xanthohumol, a Prenylated Chalcone from Beer Hops, Acts as an $\alpha$-Glucosidase Inhibitor in Vitro. J. Agric. Food Chem. 2014, 62, 5548-5554. [CrossRef]

3. Bocquet, L.; Sahpaz, S.; Hilbert, J.L.; Rambaud, C.; Rivière, C. Humulus Lupulus L., a Very Popular Beer Ingredient and Medicinal Plant: Overview of Its Phytochemistry, Its Bioactivity, and Its Biotechnology. Phytochem. Rev. 2018, 17, 1047-1090. [CrossRef]

4. Sauerwein, H.; Meyer, H.H. D Erfassung Östrogenwirksamer Substanzen in Bier Und in Dessen Rohstoffen. Mon. Brauwiss. 1997, $50,142-146$.

5. Štulíková, K.; Karabín, M.; Nešpor, J.; Dostálek, P. Therapeutic Perspectives of 8-Prenylnaringenin, a Potent Phytoestrogen from Hops. Molecules 2018, 23, 660. [CrossRef] [PubMed]

6. Stevens, J.F.; Page, J.E. Xanthohumol and Related Prenylflavonoids from Hops and Beer: To Your Good Health! Phytochemistry 2004, 65, 1317-1330. [CrossRef] [PubMed]

7. Chen, W.; Becker, T.; Qian, F.; Ring, J. Beer and Beer Compounds: Physiological Effects on Skin Health. J. Eur. Acad. Dermatol. Venereol. 2014, 28, 142-150. [CrossRef] [PubMed]

8. Barański, M.; Średnicka-Tober, D.; Volakakis, N.; Seal, C.; Sanderson, R.; Stewart, G.B.; Benbrook, C.; Biavati, B.; Markellou, E.; Giotis, C.; et al. Higher Antioxidant and Lower Cadmium Concentrations and Lower Incidence of Pesticide Residues in Organically Grown Crops: A Systematic Literature Review and Meta-Analyses. Br. J. Nutr. 2014, 112, 794-811. [CrossRef]

9. De Keukeleire, J.; Janssens, I.; Heyerick, A.; Ghekiere, G.; Cambie, J.; Roldán-Ruiz, I.; Van Bockstaele, E.; De Keukeleire, D. Relevance of Organic Farming and Effect of Climatological Conditions on the Formation of $\alpha$-Acids, $\beta$-Acids, Desmethylxanthohumol, and Xanthohumol in Hop (Humulus lupulus L.). J. Agric. Food Chem. 2007, 55, 61-66. [CrossRef]

10. Dangour, A.D.; Dodhia, S.K.; Hayter, A.; Allen, E.; Lock, K.; Uauy, R. Nutritional Quality of Organic Foods: A Systematic Review. Am. J. Clin. Nutr. 2009, 90, 680-685. [CrossRef]

11. Brandt, K.; Leifert, C.; Sanderson, R.; Seal, C.J. Agroecosystem Management and Nutritional Quality of Plant Foods: The Case of Organic Fruits and Vegetables. Crit. Rev. Plant Sci. 2011, 30, 177-197. [CrossRef]

12. Mulet, J.M. Should We Recommend Organic Crop Foods on the Basis of Health Benefits? Letter to the Editor Regarding the Article by Barański et Al. Br. J. Nutr. 2014, 112, 1745-1747. [CrossRef] [PubMed]

13. Mlinarić, A.; Horvat, M.; Smolčić, V.Š. Dealing with the Positive Publication Bias: Why You Should Really Publish Your Negative Results. Biochem. Med. 2017, 27. [CrossRef]

14. Suñé, P.; Suñé, J.M.; Montoro, J.B. Positive Outcomes Influence the Rate and Time to Publication, but Not the Impact Factor of Publications of Clinical Trial Results. PLoS ONE 2013, 8, e54583. [CrossRef]

15. Mantha, O.L.; Laxmi Patel, M.; Hankard, R.; De Luca, A. Effect of Organic Food Intake on Nitrogen Stable Isotopes. Nutrients 2020, 12, 2965. [CrossRef] [PubMed]

16. Farquhar, G.D. On the Nature of Carbon Isotope Discrimination in C4 Species. Funct. Plant Biol. 1983, 10, 205-226. [CrossRef]

17. Brooks, J.R.; Buchmann, N.; Phillips, S.; Ehleringer, B.; Evans, R.D.; Lott, M.; Martinelli, L.A.; Pockman, W.T.; Sandquist, D.; Sparks, J.P.; et al. Heavy and Light Beer: A Carbon Isotope Approach To Detect C4 Carbon in Beers of Different Origins, Styles, and Prices. J. Agric. Food Chem. 2002, 50, 6413-6418. [CrossRef] [PubMed]

18. Mardegan, S.F.; Andrade, T.M.B.; de Sousa Neto, E.R.; de Castro Vasconcellos, E.B.; Martins, L.F.B.; Mendonça, T.G.; Martinelli, L.A. Stable Carbon Isotopic Composition of Brazilian Beers-A Comparison between Large- and Small-Scale Breweries. J. Food Compos. Anal. 2013, 29, 52-57. [CrossRef]

19. Bateman, A.S.; Kelly, S.D. Fertilizer Nitrogen Isotope Signatures. Isot. Environ. Health Stud. 2007, 43, 237-247. [CrossRef]

20. Choi, W.-J.; Ro, H.-M.; Hobbie, E.A. Patterns of Natural N-15 in Soils and Plants from Chemically and Organically Fertilized Uplands. Soil Biol. Biochem. 2003, 35, 1493-1500. [CrossRef]

21. Rogers, K.M. Nitrogen Isotopes as a Screening Tool To Determine the Growing Regimen of Some Organic and Nonorganic Supermarket Produce from New Zealand. J. Agric. Food Chem. 2008, 56, 4078-4083. [CrossRef] [PubMed]

22. Inácio, C.T.; Chalk, P.M.; Magalhães, A.M.T. Principles and Limitations of Stable Isotopes in Differentiating Organic and Conventional Foodstuffs: 1. Plant Products. Crit. Rev. Food Sci. Nutr. 2015, 55, 1206-1218. [CrossRef] [PubMed]

23. Voica, C.; Magdas, D.-A.; Feher, I. Metal Content and Stable Isotope Determination in Some Commercial Beers from Romanian Markets. J. Chem. 2015, 2015, 10. [CrossRef]

24. Ocvirk, M.; Ogrinc, N.; Košir, I.J. Determination of the Geographical and Botanical Origin of Hops (Humulus Lupulus L.) Using Stable Isotopes of C, N, and S. J. Agric. Food Chem. 2018, 66, 2021-2026. [CrossRef] 
25. Stevens, J.F.; Taylor, A.W.; Deinzer, M.L. Quantitative Analysis of Xanthohumol and Related Prenylflavonoids in Hops and Beer by Liquid Chromatography-Tandem Mass Spectrometry. J. Chromatogr. A 1999, 832, 97-107. [CrossRef]

26. Trass, M.; Koerner, P.; Layne, J. Rapid Analysis of Hop Acids in Beer Using Strata ${ }^{T M}-X$ SPE and Kinetex ${ }^{\circledR} 2.6$ Mm Core-Shell Technology; HPLC Column. Application note @Phenomenex: Torrance, CA, USA, 2011.

27. Bernal, J.; García-Mauriño, C.M.; Reglero, G.; Marin, F.R.; Ibáñez, E. Fast Screening Method to Determine Hop's Phytoestrogens in Beer. Food Anal. Methods 2011, 4, 416-423. [CrossRef]

28. Magalhães, P.J.; Guido, L.F.; Cruz, J.M.; Barros, A.A. Analysis of Xanthohumol and Isoxanthohumol in Different Hop Products by Liquid Chromatography-Diode Array Detection-Electrospray Ionization Tandem Mass Spectrometry. J. Chromatogr. A 2007, 1150, 295-301. [CrossRef] [PubMed]

29. AOAC. AOAC Guidelines for Single-Laboratory Validation of Chemical Methods for Dietary Supplements and Botanicals, Official Methods of Analysis, 19th ed.; AOAC: Gaithersburg, MD, USA, 2012.

30. Magnusson, B.; Örnemark, U. (Eds.) Eurachem Guide: The Fitness for Purpose of Analytical Methods-A Laboratory Guide to Method Validation and Related Topics, 2nd ed. 2014. Available online: Www.Eurachem.Org (accessed on 14 May 2019).

31. European Commission Commission Regulation (EC). No 401/2006, Laying down the Methods of Sampling and Analysis for the Official Control of the Levels of Mycotoxins in Foodstuffs; Official Journal of the European Communities: Brussels, Belgium, 2006.

32. European Commission. Directorate General for Health and Food Safety Guidance Document on Analytical Quality Control and Method Validation Procedures for Pesticide Residues and Analysis in Food and Feed SANTE/11813/2017; European Commission: Brussels, Belgium, 2017. 